\title{
Adaptation of colonic fermentation and glucagon-like peptide-1 secretion with increased wheat fibre intake for 1 year in hyperinsulinaemic human subjects
}

\author{
Kristin R. Freeland ${ }^{1}$, Charlotte Wilson ${ }^{1}$ and Thomas M. S. Wolever ${ }^{1,2 *}$ \\ ${ }^{1}$ Department of Nutritional Sciences, University of Toronto, Toronto, Ontario, Canada M5S $3 E 2$ \\ ${ }^{2}$ Li Ka Shing Knowledge Institute and Division of Endocrinology and Metabolism, Department of Medicine, St Michael's Hospital, \\ Toronto, Ontario, Canada M5B 1 W8
}

(Received 19 November 2008 - Revised 29 April 2009 - Accepted 1 June 2009 - First published online 7 August 2009)

High cereal fibre intake is associated with reduced risk for type 2 diabetes, but wheat fibre had little or no effect on glycaemic control or oral glucose tolerance in clinical trials lasting 4-12 weeks. To explain this discrepancy, we hypothesised that colonic adaptation to increased wheat fibre intake takes many months but eventually results in increased SCFA production and glucagon-like peptide-1 (GLP-1) secretion. Thus, the primary objective was to determine the time-course of the effects of increased wheat fibre intake on plasma acetate, butyrate and GLP-1 concentrations in hyperinsulinaemic human subjects over 1 year. Subjects with fasting plasma insulin $\geq 40$ pmol/l were randomly assigned by computer to receive either a high-wheat fibre cereal (fibre group; $24 \mathrm{~g}$ fibre/d; twenty assigned; six dropped out, fourteen included) or a lowfibre cereal (control group; twenty assigned; six dropped-out, fourteen included) daily for 1 year. Acetate, butyrate and GLP-1 were measured during $8 \mathrm{~h}$ metabolic profiles performed every 3 months. There were no differences in body weight in the fibre group compared with the control group. After 9 months baseline-adjusted mean $8 \mathrm{~h}$ acetate and butyrate concentrations were higher on the high-fibre than the control cereal $(P<0 \cdot 05)$. After 12 months on the high-fibre cereal, baseline-adjusted mean plasma GLP-1 was $1.3(95 \% \mathrm{CI} 0 \cdot 4,2 \cdot 2)$ pmol/1 $(P<0 \cdot 05)$ higher than at baseline (about $25 \%$ increase) and $1.4(95 \%$ CI $0 \cdot 1,2.7)$ pmol/l $(P<0.05)$ higher than after 12 months on control. It is concluded that wheat fibre increased SCFA production and GLP-1 secretion in hyperinsulinaemic humans, but these effects took 9-12 months to develop. Since GLP-1 may increase insulin sensitivity and secretion, these results may provide a mechanism for the epidemiological association between high cereal fibre intake and reduced risk for diabetes.

Randomised controlled clinical trials: Human studies: Dietary fibre: Colonic fermentation: Glucagon-like peptide-1: Insulin resistance

High cereal fibre intake is linked to reduced risk of developing type 2 diabetes, increased insulin sensitivity and reduced weight gain $^{(1-3)}$. The source of cereal fibre in these studies is not clear, but the majority is probably wheat fibre; about $70 \%$ of the servings of foods in the highest quintile of cereal fibre intake in US nurses consisted of dark bread, wheat germ and wheat bran ${ }^{(4)}$, and, in Europe, cereal fibre intake was more strongly correlated with wholegrain bread $\left(\begin{array}{ll}r & 0.71\end{array}\right)$ than muesli $\left(\begin{array}{ll}r & 0 \cdot 34\end{array}\right)^{(3)}$. Recent studies have shown that various types of cereal fibre influence acute postprandial glucose, insulin and gut hormone responses ${ }^{(5)}$, and improve insulin sensitivity in studies lasting $1-3 \mathrm{~d}^{(6,7)}$. However, controlled clinical trials lasting 4-12 weeks showed no significant effect of wheat fibre on glycaemic control or oral glucose tolerance in normal ${ }^{(8,9)}$ or diabetic subjects ${ }^{(10,11)}$. This suggests that the short-term effects of cereal fibre may not persist or that other mechanisms are involved. The discrepancy in results between prospective studies and 4- to 12-week clinical trials suggests that it may take a long time for the protective effects of cereal fibre to develop. Animal studies suggest that fibre may protect against diabetes due to an ability of the SCFA (acetic, propionic and butyric acids), produced during the colonic fermentation of dietary fibre ${ }^{(12)}$, to increase the production of glucagon-like peptide-1 (GLP-1) ${ }^{(13,14)}$. GLP-1 stimulates insulin secretion, reduces the rate of gastric emptying, increases insulin sensitivity and reduces energy intake ${ }^{(15)}$.

The colon, containing thousands of bacterial phylotypes ${ }^{(16)}$, represents a complex ecosystem; when such systems are disturbed it takes a long time for equilibrium to be re-established $^{(17)}$. In rats fed resistant starch for 6 months, caecal SCFA concentrations continued to increase over the duration of the study ${ }^{(18)}$. In human subjects with diabetes it took 6-9 months for fasting plasma acetate to start rising after increased fibre intake ${ }^{(19)}$ or on long-term acarbose therapy ${ }^{(20)}$. In human subjects, high-fibre diets ${ }^{(21)}$ increased plasma acetate and butyrate, but not propionate. This may be because acetate is the most abundant SCFA ${ }^{(21)}$ and high amounts of butyrate are produced when starch is fermented ${ }^{(22)}$. Wheat bran is generally considered to be partly fermented ${ }^{(23)}$, with about $45 \%$ disappearing from the human gastrointestinal tract over a $12 \mathrm{~d}$ feeding period ${ }^{(24)}$; however, wheat fibre fermentability may increase with long-term consumption due to adaptation of colonic bacteria. 
Thus, our primary objective was to determine the timecourse of the effects of increased wheat fibre intake on plasma acetate, butyrate and GLP-1 concentrations in hyperinsulinaemic human subjects. Hyperinsulinaemic subjects were studied because high plasma insulin is typically associated with insulin resistance ${ }^{(25)}$ and increased risk for diabetes ${ }^{(26)}$; thus, they would be likely to benefit from any protective effect of fibre. We hypothesised that it would take 6-9 months for significant increases in plasma SCFA and GLP-1 concentrations to be detected.

\section{Materials and methods}

Healthy subjects ( $n$ 40) with fasting plasma insulin $\geq 40$ $\mathrm{pmol} / \mathrm{l}$ were recruited from the Toronto area through newspaper advertisements. No subjects had used antibiotics in the last 3 months, had any history of gastrointestinal problems, diabetes, hyperlipidaemia or a high-fibre diet.

Subjects, stratified by sex, were randomised to a high-wheat fibre cereal (fibre group) (All Bran Original ${ }^{\circledR}$; Kellogg Canada Inc., Mississauga, ON, USA) or a low-fibre cereal (control group) (Rice Krispies ${ }^{\circledR}$; Kellogg Canada Inc.) using blocks of unequal sizes to enhance concealment. Random treatment allocations were created using the @RAND function of Lotus 123 (Lotus Development Corp., Cambridge, MA, USA) and sealed in opaque envelopes which were opened on the morning of the baseline metabolic profile in the order of each subject's arrival. Thereafter, subjects were asked to consume $60 \mathrm{~g}$ of the high-fibre cereal $(750 \mathrm{~kJ}, 30 \mathrm{~g}$ carbohydrate, $24 \mathrm{~g}$ fibre, $2 \mathrm{~g}$ fat and $8 \mathrm{~g}$ protein) or $49 \mathrm{~g}$ of the control cereal $(750 \mathrm{~kJ}, 41 \mathrm{~g}$ carbohydrate, $0.5 \mathrm{~g}$ fibre, $1 \mathrm{~g}$ fat and $3 \mathrm{~g}$ protein) daily for 1 year. Apart from the high-fibre cereal or the control cereal, subjects consumed self-selected diets with no restrictions, except that they were asked to maintain constant weight and physical activity throughout the study. At monthly intervals subjects were weighed, picked up supplies of cereal and returned unused cereal from the previous month.

At baseline, 3, 6, 9 and 12 months, overnight-fasted subjects came to St Michael's Hospital at about 08.00 hours for an $8 \mathrm{~h}$ metabolic profile. At baseline each subject received their assigned cereal for breakfast and chose the remainder of their breakfast and lunch from a fixed menu. The breakfast menu included white bread or toast with margarine, $2 \%$ milk, orange or apple juice, and/or tea or decaffeinated coffee with sugar or sweetener. The lunch menu consisted of one of four frozen entrées, white bread, margarine, baby carrots, $2 \%$ milk, orange or apple juice, cookies (digestive or chocolate chip), tea or decaffeinated coffee with sugar or sweetener, and/or pudding (vanilla or chocolate). Nutrient intakes during the metabolic-profile days for subjects on the fibre cereal $v$. the control cereal, respectively, were: energy, 4010 (SEM 192) v. 4900 (SEM 377) kJ; fat, 23 (SEM 2) v. 28 (SEM 3) g; protein, 37 (SEM 1) v. 37 (SEM 3) g; carbohydrate, 171 (SEM 8) v. 196 (SEM 14) g; dietary fibre, 26 (SEM 0) v. 9 (SEM 1) g. The only significant differences were for energy and fibre. For each subject, the exact amounts and types of foods chosen on the first test day were repeated on the 4 remaining test days. Three-day diet records for 2 weekdays and 1 weekend day were collected on test days. Nutrient intakes were analysed using Food Processor SQL ${ }^{\circledR}$ version
9.9.1 (ESHA Research, Salem, OR, USA). Throughout the present paper the term 'carbohydrate' means available carbohydrate defined as total carbohydrate minus dietary fibre. Physical activity was assessed on test days by asking subjects about type and frequency of regular exercise. This information was used to ensure that subjects maintained physical activity levels throughout the study.

On each metabolic profile day, subjects were weighed, gave a fasting blood sample, ate breakfast and had further blood taken $0 \cdot 5,1,2,3,4,5,6,7$ and $8 \mathrm{~h}$ after the start of breakfast from a cannulated forearm vein (cannula kept open with sterile saline). Lunch was consumed after the $4 \mathrm{~h}$ blood sample. Blood for glucose, insulin, NEFA and SCFA was taken into fluro-oxalate tubes. Blood for GLP-1 was taken into icecooled EDTA tubes at $0,0 \cdot 5,1,2,4$ and $5 \mathrm{~h}$, and $50 \mu \mathrm{l}$ of dipeptidyl peptidase-4 (DPP-IV) inhibitor (Linco Research, Billerica, MA, USA) added within $30 \mathrm{~s}$ of collection. Blood samples were centrifuged at $4^{\circ} \mathrm{C}$, and the plasma removed and stored at $-70^{\circ} \mathrm{C}$ until analysis.

Glucose was measured by a hexokinase method, insulin by electrochemiluminescence immunoassay (Roche Diagnostics, Mannheim, Germany), NEFA enzymically (Wako Chemical Industries, Dallas, TX, USA) and GLP-1 by ELISA which captures active GLP-1 (7-36 amide) by a monoclonal antibody with specific binding to the $\mathrm{N}$-terminal region of the molecule (Linco Research, Billerica, MA, USA).

Before SCFA analysis plasma samples were filtered through a micro-partition system with a $30000 \mathrm{Da}$ molecular-weight cut-off (Vivaspin 2; Vivascience, Hanover, Germany) by centrifuging at $5000 \mathrm{~g}$ at $4^{\circ} \mathrm{C}$ for $90 \mathrm{~min}$ and the protein-free filtrate stored at $-70^{\circ} \mathrm{C}$. Before use, the filters were washed by centrifuging three times with doubly distilled, deionised water, to remove contaminants that interfered with butyrate and propionate peaks. Samples $(225 \mu l)$ of protein-free plasma were vacuum distilled after adding $25 \mu \mathrm{l}$ internal standard (1.25 mM-2-ethyl butyric acid and $1 \mathrm{M}-\left[{ }^{2} \mathrm{H}\right]$ formic acid; Cambridge Isotope Laboratories, Xenia, OH, USA). The distilled samples were stored on dry ice until analysis later the same day. An HP 7673 or HP 7683 auto-sampler (Hewlett Packard, Mississauga, ON, Canada) was used to inject $0.5 \mu \mathrm{l}$ of sample into an HP 5890 Series II or HP $6890 \mathrm{~N}$ gas chromatograph equipped with hot $\left(130^{\circ} \mathrm{C}\right)$ on-column inlets, an Agilent 19095F-123 PEG column $(30 \mathrm{~m} \times 0.53 \mathrm{~m} \times 1.0 \mu \mathrm{m}$ film; Agilent, Mississauga, ON, Canada) and flame ionisation detector. The column temperature was initially $80^{\circ} \mathrm{C}$ and rose to $220^{\circ} \mathrm{C}$. The carrier gas was $\mathrm{He}$ and the detector received $\mathrm{He}$, $\mathrm{H}_{2}$ and air. Protein-free plasma samples were distilled in duplicate and each distillate injected in triplicate. SCFA concentrations were determined from the peak height ratio for each SCFA (average of 6) $v$. the internal standard, with reference to standard curves and corrected for dilution during sample preparation.

We studied thirty subjects because, based on a previous study $^{(12)}$, this number provided $80 \%$ power to detect changes in postprandial acetate and butyrate responses. The results of subjects who dropped out of the study ( $n$ 12) before the 3 -month metabolic profile were not included. Differences in subject characteristics, compliance and nutrient intakes at baseline and during the study (mean of 3, 6,9 and 12 months) in the fibre group compared with the control group were assessed by the unpaired $t$ test. Differences in dietary fibre 
intake were also assessed for the effect of group and time as a two-factor analysis of covariance (ANCOVA), where baseline was the covariate, using the SAS ${ }^{\circledR}$ (SAS Institute, Inc., Cary, NC, USA) procedure for mixed models.

Changes from baseline in SCFA and GLP-1 concentrations at individual time points during the metabolic profile were considered as secondary endpoints, and compared by the paired $t$ test. The conclusions were based on the mean $0-8 \mathrm{~h}$ concentrations of glucose, insulin, NEFA and SCFA, and $0-5 \mathrm{~h}$ for GLP-1, determined as total area under the response curve divided by the time interval ( $8 \mathrm{~h}$ or $5 \mathrm{~h}$ ). Missing values (four from the fibre group and five from the control group, due to drop-outs or subjects who missed tests) were imputed by averaging the preceding and following values or, if the missing value was the final value, then the last value was carried forward. The degrees of freedom were reduced by the number of missing values. Two $0-5 \mathrm{~h}$ mean GLP-1 values were removed from the analysis (one from each group) because they were $>3 \mathrm{SD}$ from the mean. Data were assessed for normality using the SAS ${ }^{\circledR}$ univariate procedure and a logarithmic transformation applied to non-normally distributed variables before conducting further statistical analyses. Differences in body weight and the metabolic endpoints were examined for the effect of group and time as a two-factor ANCOVA, where baseline was the covariate, using the SAS ${ }^{\circledR}$ procedure for mixed models. If the interaction between group and time was significant, unpaired $t$ tests were performed at each time point to assess the effect of group.

Results are expressed as mean values with their standard errors or mean values with $95 \%$ CI. Unless otherwise indicated, differences between means are considered significant at $P<0.05$.

The present study was conducted according to the guidelines laid down in the Declaration of Helsinki and all procedures involving human subjects were approved by the ethics committees at the University of Toronto and $\mathrm{St}$ Michael's Hospital. Written informed consent was obtained from all subjects.

\section{Results}

A total of 171 individuals were screened to participate in the study, sixty-six were eligible, forty were recruited to participate and twenty-eight subjects were included in the final analysis (Fig. 1). At baseline, subjects randomised to the fibre group had lower fasting and postprandial insulin and lower

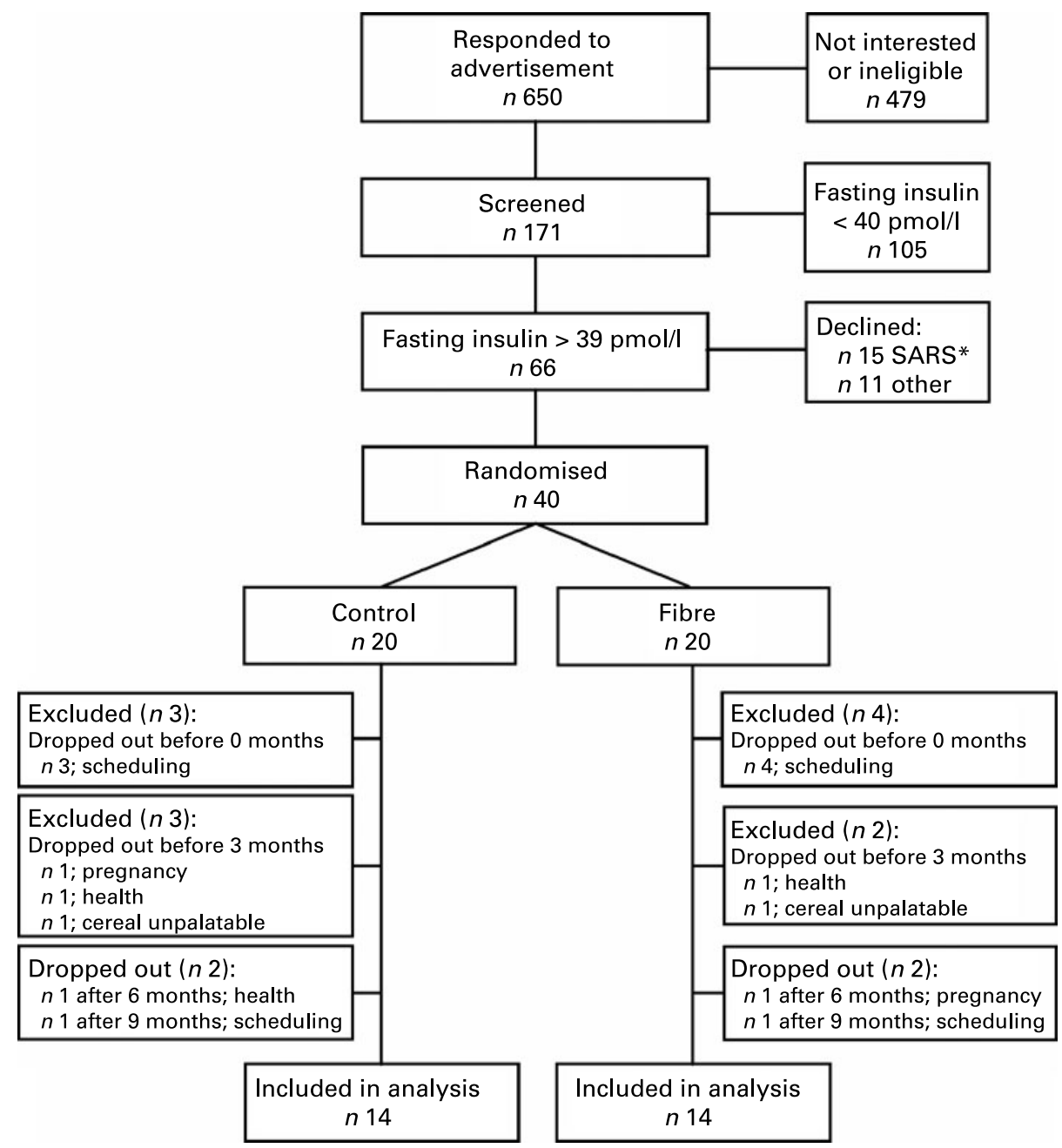

Fig. 1. Study flow chart. * The 2003 epidemic of severe acute respiratory syndrome (SARS) in Toronto resulted in a temporary halt of all clinical research. After the epidemic was over, fifteen previously recruited subjects declined to participate. 
homeostasis model assessment of insulin resistance (HOMAr) than those randomised to the control group, but did not differ significantly for any other anthropometric or metabolic variable (Table 1).

The fibre group consumed 98 (SEM 4) \% of the prescribed amount of high-fibre cereal, resulting in an increase in total fibre intake of $20 \mathrm{~g} / \mathrm{d}$ (Table 2). The control group consumed more cereal than requested, and so had significantly higher compliance than the fibre group (116 (SEM 5) \%; $P=0 \cdot 01$ ). At baseline there were no significant differences between the fibre and the control groups for mean daily intake of nutrients. During the trial the fibre group consumed significantly more total and soluble dietary fibre than the control group, but there were no other differences in nutrient intakes (Table 2). Body weight tended to increase in both groups throughout the trial, but neither the change with time, nor the difference between the fibre and the control group was statistically significant (baseline $v .1$ year, respectively, for the fibre group: 78.5 (SEM 4.2) v. 79.7 (SEM 4.1) kg and the control group: $80 \cdot 5$ (SEM 5.6) v. $81 \cdot 8$ (SEM 6.1) $\mathrm{kg}$ ).

After 12 months on the control cereal, plasma acetate was significantly higher than baseline at several times throughout the day, while on the high-fibre cereal this was only significant at $8 \mathrm{~h}$ (Fig. 2). Propionate tended to increase from baseline in both the control and fibre groups, with significant differences at several times in the fibre group. Butyrate tended to be lower than baseline after 12 months on the control cereal, but higher

Table 1. Subject characteristics at baseline

(Mean values with their standard errors)

\begin{tabular}{|c|c|c|c|c|}
\hline \multirow[t]{2}{*}{ Group... } & \multicolumn{2}{|c|}{$\begin{array}{l}\text { High-wheat } \\
\text { fibre cereal }\end{array}$} & \multicolumn{2}{|c|}{$\begin{array}{l}\text { Low-fibre cereal } \\
\quad \text { (control) }\end{array}$} \\
\hline & Mean & SEM & Mean & SEM \\
\hline \multicolumn{5}{|l|}{ Subjects $(n)$} \\
\hline Male & \multicolumn{2}{|c|}{3} & \multicolumn{2}{|c|}{3} \\
\hline Female & \multicolumn{2}{|c|}{11} & \multicolumn{2}{|c|}{11} \\
\hline Age (years) & 31.6 & 3.5 & $26 \cdot 5$ & $2 \cdot 7$ \\
\hline $\mathrm{BMI}\left(\mathrm{kg} / \mathrm{m}^{2}\right)$ & $25 \cdot 7$ & $1 \cdot 1$ & $26 \cdot 1$ & 1.3 \\
\hline Waist circumference $(\mathrm{cm})$ & $82 \cdot 3$ & $3 \cdot 3$ & 83.7 & $3 \cdot 8$ \\
\hline $\mathrm{HbA} 1 \mathrm{c}(\%)$ & $5 \cdot 0$ & 0.0 & $5 \cdot 1$ & 0.0 \\
\hline Fasting glucose $(\mathrm{mmol} / \mathrm{l})$ & $5 \cdot 6$ & 0.2 & $5 \cdot 3$ & 0.2 \\
\hline $0-8 \mathrm{~h}$ Glucose $(\mathrm{mmol} / \mathrm{l})$ & 5.9 & 0.2 & $5 \cdot 8$ & 0.1 \\
\hline \multicolumn{5}{|l|}{ Fasting insulin $(\mathrm{pmol} / \mathrm{l}) \dagger$} \\
\hline Median & \multirow{2}{*}{\multicolumn{2}{|c|}{$\begin{array}{c}42 \\
28-64\end{array}$}} & \multirow{2}{*}{\multicolumn{2}{|c|}{$\begin{array}{c}72^{*} \\
53-120\end{array}$}} \\
\hline Interquartile range & & & & \\
\hline \multicolumn{5}{|l|}{$0-8 \mathrm{~h}$ Insulin $(\mathrm{pmol} / \mathrm{l}) \dagger$} \\
\hline Median & \multirow{2}{*}{\multicolumn{2}{|c|}{$\begin{array}{c}207 \\
148-269\end{array}$}} & \multicolumn{2}{|c|}{$333^{\star}$} \\
\hline Interquartile range & & & & \\
\hline \multicolumn{5}{|l|}{ HOMArt } \\
\hline Median & \multirow{2}{*}{\multicolumn{2}{|c|}{$\begin{array}{c}1 \cdot 5 \\
1 \cdot 1-2 \cdot 8\end{array}$}} & \multirow{2}{*}{\multicolumn{2}{|c|}{$\begin{array}{c}2 \cdot 7^{*} \\
2 \cdot 0-4 \cdot 8\end{array}$}} \\
\hline Interquartile range & & & & \\
\hline Fasting NEFA $(\mathrm{mmol} / \mathrm{l})$ & 0.38 & 0.06 & 0.37 & 0.05 \\
\hline $0-8 \mathrm{~h}$ NEFA $(\mathrm{mmol} / \mathrm{l})$ & 0.15 & 0.02 & 0.19 & 0.03 \\
\hline Fasting GLP-1 (pmol/l) & 3.4 & $0 \cdot 6$ & $4 \cdot 0$ & 0.7 \\
\hline $0-5 \mathrm{~h}$ GLP-1 $(\mathrm{pmol} / \mathrm{l})$ & $5 \cdot 3$ & 0.8 & $5 \cdot 8$ & 0.6 \\
\hline $0-8 \mathrm{~h}$ Acetate $(\mu \mathrm{mol} / \mathrm{l})$ & 35 & 8 & 28 & 11 \\
\hline $0-8 \mathrm{~h}$ Propionate $(\mu \mathrm{mol} / \mathrm{l})$ & $1 \cdot 7$ & $1 \cdot 1$ & 1.7 & 0.3 \\
\hline $0-8 \mathrm{~h}$ Butyrate $(\mu \mathrm{mol} / \mathrm{l})$ & 0.62 & 0.15 & 0.78 & 0.24 \\
\hline
\end{tabular}

HOMAr, homeostasis model assessment of insulin resistance; GLP-1, glucagonlike peptide-1.

* Median value was significantly different from that of the high-wheat fibre cereal group $(P<0.05)$.

†Non-normally distributed variables. than baseline after 12 months on the high-fibre cereal although none of the differences at individual time points was statistically significant (Fig. 2). After 12 months, plasma GLP-1 was no different from baseline on the control cereal, but on the high-fibre cereal increased significantly at fasting and $1 \mathrm{~h}$ (Fig. 2).

After 12 months on the control cereal, fasting and postprandial glucose tended to be higher than at baseline (significant at $2 \mathrm{~h}$ ), whereas after 12 months on the high-fibre cereal, mean fasting and postprandial glucose concentrations were virtually identical to those at baseline (Fig. 3). Fasting and postprandial insulin and NEFA did not change from baseline on either the high-fibre or the control cereal (Fig. 3).

There were significant time $\times$ treatment interactions for baseline-adjusted $0-8 \mathrm{~h}$ mean concentrations of acetate $(P=0.008)$ and butyrate $(P=0.01)$, which indicates that the differences between the control and fibre groups changed with time. There was no significant difference in baselineadjusted mean $0-8 \mathrm{~h}$ acetate between the fibre and control groups until 9 months, when the value for the fibre group, 8 $(95 \% \mathrm{CI}-4,21) \mu \mathrm{mol} / \mathrm{l}$, was greater than that for the control group, -5 (95\% CI $-10,0) \mu \mathrm{mol} / 1(P<0 \cdot 05$; Fig. 4). Similarly, after 9 months, mean $0-8 \mathrm{~h}$ butyrate had increased more for the fibre group, $0 \cdot 16(95 \%$ CI $-0 \cdot 15,0.46) \mu \mathrm{mol} / \mathrm{l}$, than for the control group, $-0.14(95 \%$ CI $-0.25,-0.02)$ $\mu \mathrm{mol} / \mathrm{l}(P<0.05$; Fig. 4).

There was a significant time $\times$ treatment interaction for $0-5 \mathrm{~h}$ mean GLP-1 concentration $(P=0 \cdot 033)$. Mean $0-5 \mathrm{~h}$ plasma GLP-1 tended to fall with time on the control cereal, but rise with time on the high-fibre cereal (Fig. 4), so that by 12 months the baseline-adjusted mean $0-5 \mathrm{~h}$ GLP-1 for the fibre group was greater than baseline by $1.3(95 \% \mathrm{CI}$ $0.4,2 \cdot 2) \mathrm{pmol} / \mathrm{l}(P<0.05)$, and greater than the value for the control group by $1.4(95 \%$ CI $0.1,2.7) \mathrm{pmol} / 1(P<0.05)$; this difference represents a $25 \%$ increase in GLP-1 on the high-fibre cereal. Baseline-adjusted mean $0-8 \mathrm{~h}$ plasma glucose tended to be lower on the high-fibre cereal than the control cereal, and the difference tended to increase with time, but this was not significant (time $\times$ treatment interaction; $P=0.78$ ) (Fig. 4). Mean 0-8h plasma insulin and NEFA appeared to be higher on the high-fibre cereal than on the control cereal, but the differences were not significant ( $P=0.99$ and $P=0.06$, respectively).

There were no significant correlations between changes in mean $0-8 \mathrm{~h}$ concentrations of GLP-1, glucose, insulin or NEFA and changes in SCFA or body weight. Neither fibre intake, nor carbohydrate intake $(\mathrm{g})$, nor percentage compliance, was correlated with any of the SCFA or GLP-1 mean concentrations throughout the study.

\section{Discussion}

The results showed that when hyperinsulinaemic human subjects increased wheat fibre intake by $20 \mathrm{~g} / \mathrm{d}$ for 1 year, mean $0-8 \mathrm{~h}$ plasma acetate did not change except for a transient increase at 9 months; it took 9 months for plasma butyrate to increase and 12 months for plasma GLP-1 to increase significantly compared with the control treatment.

One limitation of measuring SCFA in peripheral blood is that plasma SCFA originate from exogenous (i.e. colonic fermentation) and endogenous sources. Acetate and butyrate 
Table 2. Nutrient intakes at baseline and during the study (Mean values with their standard errors)

\begin{tabular}{|c|c|c|c|c|c|c|c|c|}
\hline \multirow{3}{*}{ Group... } & \multicolumn{4}{|c|}{ Baseline } & \multicolumn{4}{|c|}{ Study } \\
\hline & \multicolumn{2}{|c|}{$\begin{array}{c}\text { High-wheat fibre } \\
\text { cereal }(n 14)\end{array}$} & \multicolumn{2}{|c|}{$\begin{array}{l}\text { Low-fire cereal } \\
\text { (control) }(n 14)\end{array}$} & \multicolumn{2}{|c|}{$\begin{array}{c}\text { High-wheat fibre } \\
\text { cereal }(n 14)\end{array}$} & \multicolumn{2}{|c|}{$\begin{array}{c}\text { Low-fibre cereal } \\
\text { (control) }(n 14)\end{array}$} \\
\hline & Mean & SEM & Mean & SEM & Mean & SEM & Mean & SEM \\
\hline Energy (kJ) & 7320 & 644 & 8400 & 577 & 7770 & 598 & 8380 & 635 \\
\hline Carbohydrate (g) & 215 & 23 & 261 & 19 & 253 & 22 & 262 & 23 \\
\hline Total dietary fibre $(\mathrm{g})$ & 18 & 3 & 21 & 3 & $38^{*}$ & 5 & 19 & 12 \\
\hline Soluble fibre $(\mathrm{g})$ & 0.5 & 0.1 & 0.8 & 0.1 & $0.9^{*}$ & 0.2 & 0.5 & $0 \cdot 1$ \\
\hline Protein $(\mathrm{g})$ & 74 & 6 & 81 & 6 & 80 & 6 & 84 & 6 \\
\hline Total fat (g) & 66 & 7 & 72 & 7 & 59 & 7 & 69 & 9 \\
\hline Polyunsaturated fat $(\mathrm{g})$ & 8 & 1 & 10 & 1 & 8 & 1 & 10 & 2 \\
\hline Monounsaturated fat (g) & 17 & 2 & 21 & 2 & 15 & 2 & 19 & 3 \\
\hline Saturated fat $(\mathrm{g})$ & 22 & 3 & 22 & 2 & 19 & 3 & 23 & 1 \\
\hline $\mathrm{Mg}(\mathrm{mg})$ & 243 & 39 & 239 & 29 & 437 & 49 & 313 & 75 \\
\hline
\end{tabular}

${ }^{*}$ Mean value was significantly different from that at baseline for the high-fibre group and from the study value for the control group $(P<0.05)$. No other differences were statistically significant.

are produced by fat oxidation, while propionate comes from branched-chain amino acid and methionine metabolism ${ }^{(27)}$. Thus, increased plasma SCFA concentrations occur during states of enhanced fat and amino acid oxidation, such as

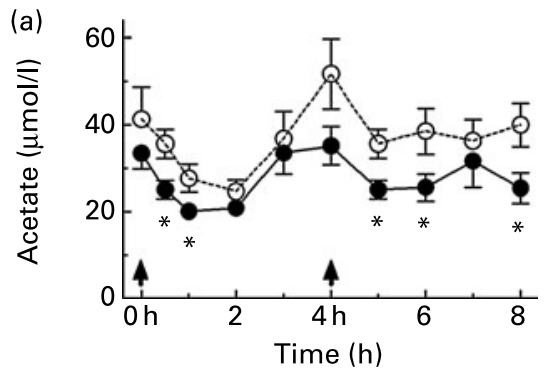

(c)
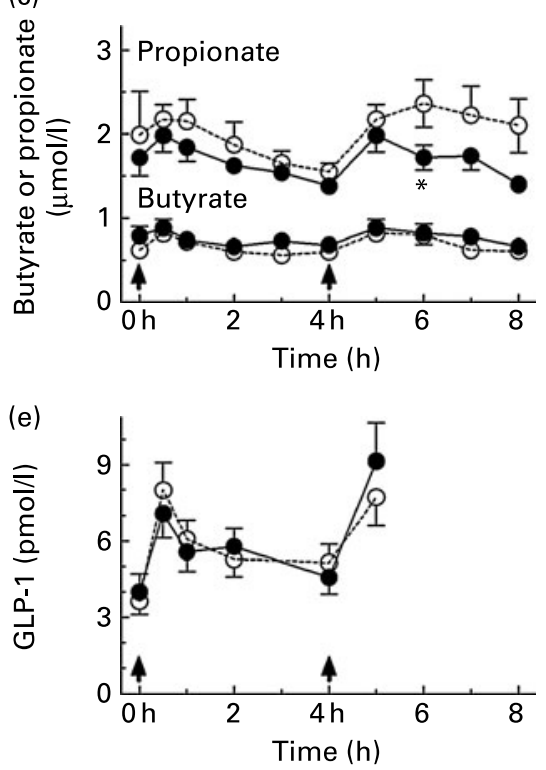

prolonged starvation ${ }^{(28)}$, diabetes ${ }^{(29)}$ and impaired glucose tolerance $^{(30)}$. It has generally been considered that, under normal circumstances, colonic fermentation is the primary source of blood acetate ${ }^{(29)}$. However, in the present and
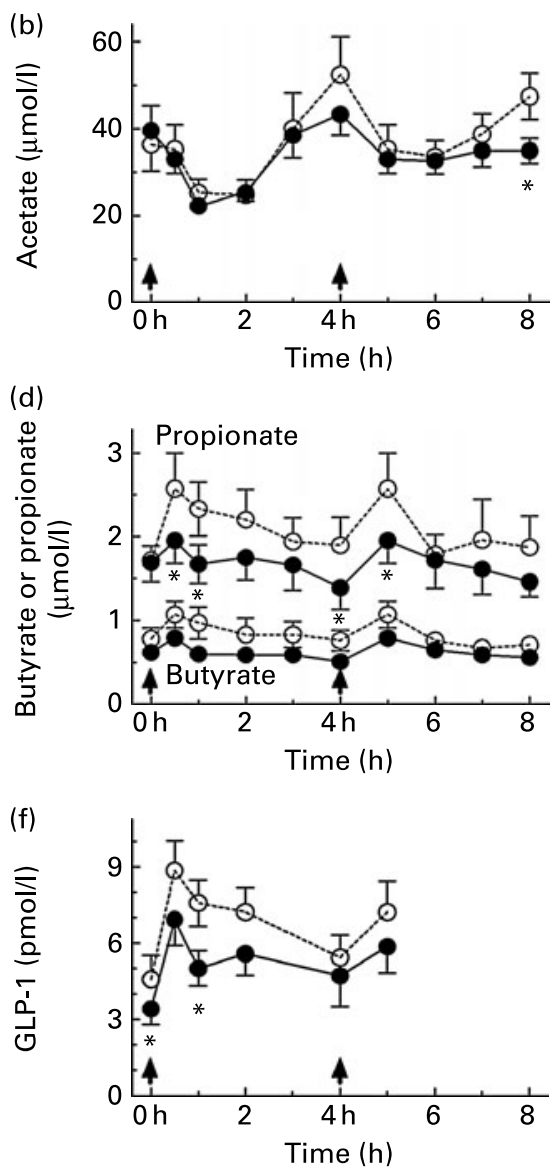

Fig. 2. Fasting and postprandial concentrations of plasma acetate ( $a$ and b), butyrate and propionate (c and d) and glucagon-like peptide-1 (GLP-1) (e and f) during $8 \mathrm{~h}$ metabolic profiles at baseline $(\bullet)$ and after 12 months $(O)$ on a low-fibre cereal (a, c, e; $n$ 14) or a high-wheat fibre cereal (b, d, f; $n$ 14). $\uparrow$, Times of meal consumption. Values are means, with standard errors represented by vertical bars. ${ }^{*}$ Mean value was significantly different from that at 12 months $(P<0.05$; paired $t$ test). 

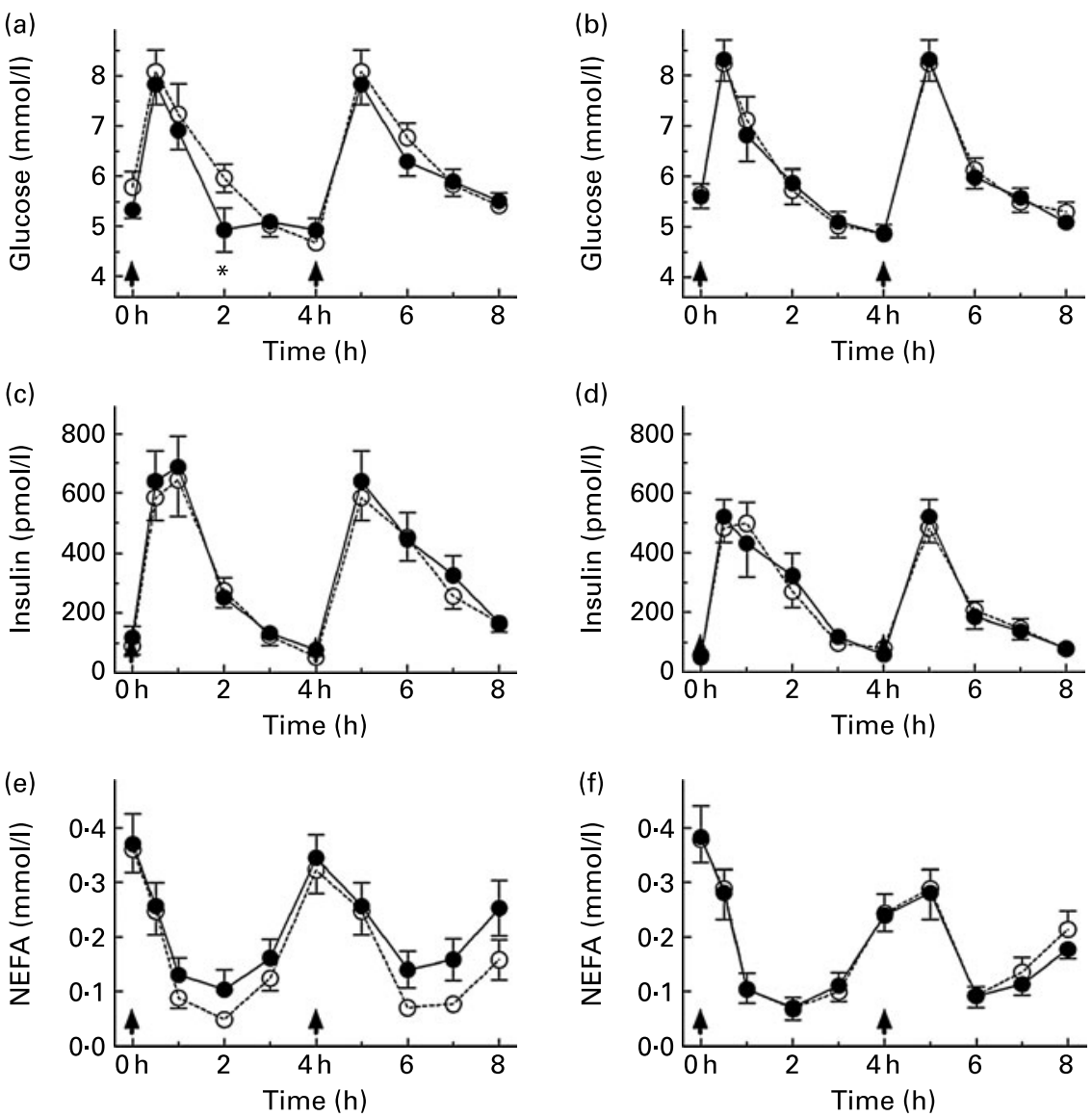

Fig. 3. Fasting and postprandial concentrations of plasma glucose (a and b), insulin (c and d) and NEFA (e and f) during $8 \mathrm{~h}$ metabolic profiles at baseline (๑) and after 12 months $(O)$ on a low-fibre cereal $(a, c, e ; n$ 14) or high-wheat fibre cereal (b, d, $f ; n$ 14). $\uparrow$, Times of meal consumption. Values are means, with standard errors represented by vertical bars. ${ }^{*}$ Mean value was significantly different from that at 12 months $(P<0.05$; paired $t$ test $)$

previous studies ${ }^{(31)}$ plasma acetate concentrations fell after breakfast, rebounded before lunch, and then fell again after lunch, a pattern of response identical to that of NEFA which are suppressed by postprandial insulin. This suggests that a substantial proportion of fasting plasma acetate is endogenously produced from fat oxidation. In this context, it is of interest that after 9 months on the high-fibre cereal, acetate increased postprandially, particularly from $4-8 \mathrm{~h}$, a time of day when increased colonic SCFA production is thought to occur $^{(31)}$. However, the tendency for plasma acetate to rise on the control cereal at 12 months was due to an increase in fasting and early postprandial acetate (Fig. 2) which might indicate increased endogenous production associated with the tendency toward increased plasma glucose at this time (Fig. 3). By contrast, plasma butyrate did not fall after eating, suggesting little or no contribution of endogenous production to the fasting butyrate level, and the increased mean $0-8 \mathrm{~h}$ concentrations after 9 and 12 months on the highfibre cereal were due to increases after breakfast and particularly after lunch.

Another limitation of measuring SCFA in peripheral blood is that butyrate is extensively metabolised in the colonic mucosa $a^{(31)}$ and all three SCFA are taken up by the liver ${ }^{(32)}$; thus peripheral blood levels may not reflect colonic production. The concentration of butyrate, in particular, is very low in peripheral blood ${ }^{(30)}$; nevertheless, we consistently have detected rises in serum butyrate on high-fibre diets ${ }^{(21)}$ and acarbose therapy ${ }^{(33)}$. In addition, studies in pigs suggest that peripheral blood butyrate concentrations mimic production rates in the colon ${ }^{(34)}$. We did not measure breath $\mathrm{H}_{2}$ because it may not be a marker of fibre fermentation. Consuming $15 \mathrm{~g}$ of various types of fermentable and non-fermentable fibre elicited no rise in breath $\mathrm{H}_{2}$ in any case ${ }^{(35)}$. When we simultaneously measured serum acetate and breath $\mathrm{H}_{2}$, we found that $20 \mathrm{~g}$ guar gum increased serum acetate in the absence of a breath $\mathrm{H}_{2}$ response ${ }^{(36)}$.

The substrates for the increased colonic fermentation on the high-fibre cereal probably include both wheat fibre and starch. Wheat fibre intake reduces intestinal transit time ${ }^{(37)}$, which, in turn, increases the amount of starch delivered to the colon ${ }^{(38)}$. Also, in vitro fermentation of starch and wheat fibre produces both acetate and butyrate ${ }^{(39)}$. The changes in acetate and butyrate over time may represent gradual adaptation of the colonic ecosystem to a sustained increase in the amount of carbohydrate entering the system. Ecosystems are self-adaptive systems which exist under specific environmental constraints, containing many different living organisms which compete for the available supply of light, nutrients and water required to sustain their populations ${ }^{(18)}$. The colonic ecosystem is complex not only because it contains thousands of species of bacteria but also because there are several distinct environments in the caecum and proximal and 
(a)

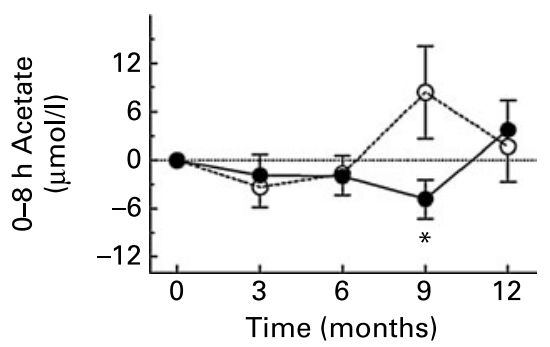

(b)

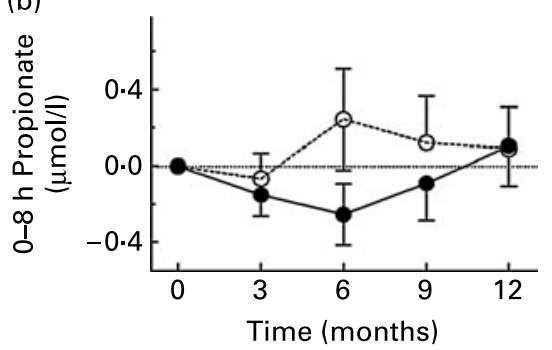

(c)

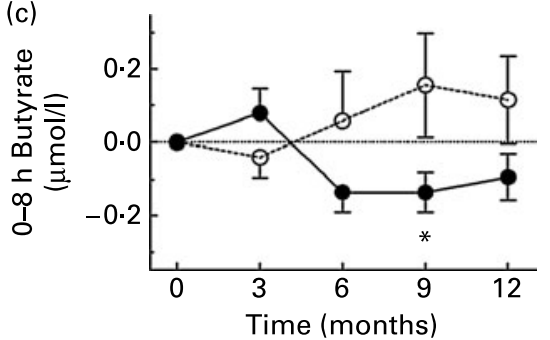

(d)
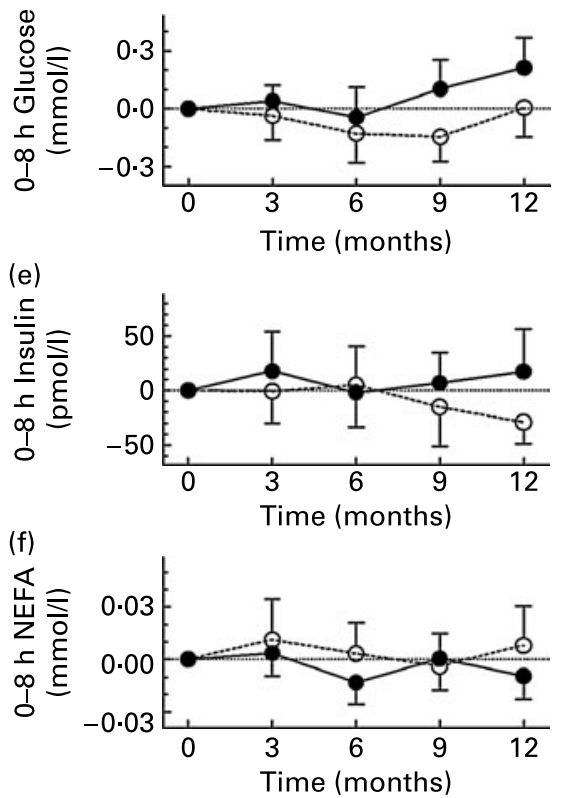

(g)

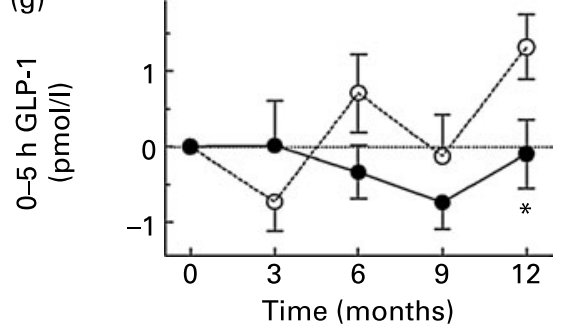

Fig. 4. Residuals of baseline-adjusted mean $0-8 \mathrm{~h}$ concentrations of plasma acetate (a), propionate (b), butyrate (c), glucose (d), insulin (e) and NEFA ( $f$ ) and mean $0-5 \mathrm{~h}$ concentrations of glucagon-like peptide-1 (GLP-1) (g) in fourteen subjects who consumed a low-fibre control cereal $(\bullet)$ and fourteen subjects who consumed a high wheat-fibre cereal $(O)$ for 1 year. Values are means, with standard errors represented by vertical bars. ${ }^{*}$ Mean value was significantly different from that of the high-fibre cereal group $(P<0.05)$. Significant time $\times$ treatment interactions existed for acetate $(P=0.008)$, butyrate $(P=0.01)$ and GLP-1 $(P=0.033)$.

distal colons ${ }^{(23)}$. A sustained change in the inputs to a complex ecosystem leads to a complex chain of events which ultimately results in a new equilibrium being reached with respect to the number and type of inhabitants of the ecosystem. The more complex the ecosystem, the longer it takes to reach equilibrium, with several hundred steps being required for land-based ecosystems ${ }^{(18)}$.

Little is known about how the colon adapts to changes in diet, and how long it takes to reach equilibrium. However, experiments in which rats were fed resistant starch for 6 months ${ }^{(10)}$ illustrate the complexity of the changes in SCFA production which occur. Relative to the control diet, on resistant starch, at 2 weeks, 2 months and 6 months, respectively, in the caecum acetate increased by 50, 20 and $100 \%$, propionate did not change and butyrate increased by 130,490 and $870 \%$. In the proximal colon acetate increased by 60,60 and $120 \%$, propionate did not change and butyrate increased by 130,600 and $990 \%$, while in the distal colon acetate increased by 200 , 50 and $240 \%$, propionate by 50,20 and $60 \%$ and butyrate by 40,600 and $1400 \%$, respectively. The magnitude of changes in specific SCFA varied with time and in different parts of the colon; however, the most consistent change, in agreement with the present results, was a gradual increase in the butyrate concentration with time in all parts of the colon. Also in agreement is a study showing an increase in the levels of butyrate in the distal colon of rats fed wheat fibre ${ }^{(40)}$.

The decline in acetate at 12 months in the fibre group was not associated with any significant reduction in fibre intake. However, it may reflect long-term adaptation of the colonic ecosystem. Certain butyrate-producing bacteria metabolise acetate produced by other bacteria ${ }^{(41)}$. Thus, it is possible to speculate that a sustained increase in acetate production leads to the proliferation of bacterial species which convert acetate to butyrate, making less acetate available for absorption into the systemic circulation. We were unable to assess whether the colonic flora changed in the present study because the faecal samples collected for this purpose were lost. However, previous research has shown that colonic bacteria change with changes in diet; for example, feeding rats starch led to increases in Lactobacillus acidophilus, L. plantarum and Bifidobacterium sp., whereas other species were unaffected ${ }^{(42)}$. In addition, the specific ability of inulin and fructo-oligosaccharides to increase Bifidobacterium sp. in the human colon is well known ${ }^{(43)}$.

GLP-1, produced from post-translational modification of proglucagon, is secreted by intestinal L-cells located throughout the intestine, but whose concentration increases progressively from the distal jejunum to the distal ileum and from the 
proximal colon to the distal colon ${ }^{(44)}$. The rise in plasma GLP-1 on wheat fibre is consistent with animal data showing that high-fibre diets or butyrate administration increase ileal and colonic proglucagon mRNA in rats ${ }^{(15)}$ and $\operatorname{dogs}^{(45)}$ and an increase in postprandial GLP-1 concentrations in rats ${ }^{(15)}$. SCFA stimulate the growth of the intestinal mucosa ${ }^{(46)}$ and oligofructose doubled the number of L-cells in the proximal colon of rats ${ }^{(47)}$, possibly by promoting differentiation via the SCFA receptor GPR43 expressed on L-cells ${ }^{(48)}$. Therefore, the gradual rise in plasma GLP-1 after wheat fibre feeding seen in the present study may have been due to a proliferative effect of SCFA on the intestinal lumen or a direct effect on intestinal L-cells.

GLP-1 secretion may be reduced in insulin resistance ${ }^{(49)}$ and obesity ${ }^{(50)}$, but it is not known if decreased GLP-1 secretion is a cause or an effect of obesity and insulin resistance. GLP-1 suppresses appetite, increases insulin secretion and reduces insulin resistance ${ }^{(17)}$. On the other hand, the high plasma insulin concentrations associated with insulin resistance may inhibit the release of gut glucagon-like immunoreactivity (an indicator of L-cell secretory activity) ${ }^{(51)}$ and leptin resistance, a common feature of obesity, may have the same effect ${ }^{(52)}$. The subjects in the present study were insulin resistant and some were obese, and therefore probably leptin resistant; nevertheless, increasing wheat fibre intake increased GLP-1 secretion. This may help to explain why cereal fibre protects against the development of obesity and diabetes ${ }^{(1,2)}$. In addition to increasing GLP-1, there may be other mechanisms by which cereal fibre or colonic fermentation may prevent diabetes; for example, some investigators have found that short-term consumption of cereal fibre $(24-72 \mathrm{~h})^{(6,7)}$ or resistant starch (4 weeks) ${ }^{(53)}$ may improve insulin sensitivity without affecting GLP-1. The fact that subjects in the fibre group did not lose weight is not inconsistent with our hypothesis since our objective was not to induce weight loss but rather to examine a possible mechanism by which fibre may maintain weight or lessen weight gain over time. Colonic SCFA provide energy to the body which may explain why weight was not lost despite increased GLP-1. Since highfibre diets increase the weight of the intestine ${ }^{(43)}$, there may have been a small loss of body fat in subjects in the fibre group which was offset by increased intestinal mass. Finally, bran products vary in their content of starch, lipids, proteins and micronutrients, and thus different types may not have the same effects as the source of wheat fibre used here.

We conclude that a sustained increase in wheat fibre intake increases plasma butyrate and GLP-1 concentrations in hyperinsulinaemic subjects, but that it takes 9-12 months for these changes to occur. These results may provide a mechanism for the epidemiological association between high cereal fibre intake and reduced risk for diabetes.

\section{Acknowledgements}

The present study was registered at clinicaltrials.gov (no. NCT00247455; http://clinicaltrials.gov/).

The study was supported by a grant from the Canadian Diabetes Association in honor of the late Kenneth B. Palmer and by a grant from the Canadian Institutes for Health Research, Institute of Nutrition, Metabolism and Diabetes - Obesity/ Healthy Body Weight Grant no. OOP-64648.
K. R. F. and T. M. S. W. conceived of the study; T. M. S. W. obtained funding; K. R. F. and C. W. collected the data; K. R. F. and T. M. S. W. performed the statistical analysis; K. R. F. drafted the paper; T. M. S. W. and C. W. revised and reviewed the paper for critical content.

None of the authors declares any conflict of interest.

\section{References}

1. Ludwig DS, Pereira MA, Kroenke CH, et al. (1999) Dietary fiber, weight gain, and cardiovascular risk factors in young adults. JAMA 282, 1539-1546.

2. Liu S, Willet WC, Manson JE, et al. (2003) Relation between changes in intakes of dietary fiber and grain products and changes in weight and development of obesity among middleaged women. Am J Clin Nutr 87, 920-927.

3. Schulze MB, Schulz M, Heidemann C, et al. (2007) Fiber and magnesium intake and incidence of type 2 diabetes. Arch Intern Med 167, 956-965.

4. Liu S, Stampfer MJ, Hu FB, et al. (1999) Whole-grain consumption and risk of coronary heart disease: results from the Nurses' Health Study. Am J Clin Nutr 70, 412-419.

5. Weickert MO \& Pfeiffer AFH (2008) Metabolic effects of dietary fiber consumption and prevention of diabetes. J Nutr 138, 439-442.

6. Weickert MO, Mohlig M, Koebnick C, et al. (2005) Impact of cereal fibre on glucose-regulating factors. Diabetologia 48, $2343-2353$.

7. Weickert MO, Möhlig M, Schöfl C, et al. (2006) Cereal fiber improves whole-body insulin sensitivity in overweight and obese women. Diabetes Care 29, 775-780.

8. Munoz JM, Sandstead HH \& Jacob RA (1979) Effects of dietary fiber on glucose tolerance of normal men. Diabetes 28, 496-502.

9. Kestin M, Moss R, Clifton PM, et al. (1990) Comparative effects of three cereal brans on plasma lipids, blood pressure, and glucose metabolism in mildly hypercholesterolemic men. Am J Clin Nutr 52, 661-666.

10. Jenkins DJA, Kendall CWC, Augustin LSA, et al. (2002) Effect of wheat bran on glycaemic control and risk factors for cardiovascular disease in type 2 diabetes. Diabetes Care 25, $1522-1528$.

11. Costabile A, Klinder A, Fava F, et al. (2008) Whole-grain wheat breakfast cereal has a prebiotic effect on the human gut microbiota: a double-blind, placebo-controlled, crossover study. $\mathrm{Br} J$ Nutr 99, 110-120.

12. Wong JMW, deSouza R, Kendall CWC, et al. (2006) Colonic health: fermentation and short chain fatty acids. J Clin Gastroenterol 40, 235-243.

13. Reimer RA \& McBurney MI (1996) Dietary fiber modulates intestinal proglucagon messenger ribonucleic acid and postprandial secretion of glucagon-like peptide-1 and insulin in rats. Endocrinology 137, 3948-3956.

14. Tappenden KA, Thomson AB, Wild GE, et al. (1996) Shortchain fatty acids increase proglucagon and ornithine decarboxylase messenger RNAs after intestinal resection in rats. JPEN $\mathbf{2 0}$, 357-362.

15. Drucker DJ (1998) Glucagon-like peptides. Diabetes 47, 159-169.

16. Samuel BS, Hansen EE, Manchester JK, et al. (2007) Genomic and metabolic adaptations of Methanobrevibacter smithii to the human gut. PNAS 104, 10643-10648.

17. Feng QY \& Chai LH (2008) A new statistical dynamic analysis on vegetation patterns in land ecosystems. Physica A 387, $3583-3593$. 
18. Le Blay G, Catherine Michel C, Hervé M, et al. (1999) Enhancement of butyrate production in the rat caecocolonic tract by long-term ingestion of resistant potato starch. $\mathrm{Br} \mathrm{J}$ Nutr 82, 419-426.

19. Wolever TMS, Schrade KB, Vogt JA, et al. (2002) Do colonic short-chain fatty acids contribute to the long-term adaptation of blood lipids in subjects with type 2 diabetes consuming a highfiber diet? Am J Clin Nutr 75, 1023-1030.

20. Wolever TMS, Radmard R, Chiasson J-L, et al. (1995) Oneyear acarbose therapy raises fasting serum acetate in diabetic patients. Diabet Med 12, 164-172.

21. Cummings JH, Pomare EW, Branch WJ, et al. (1987) Short chain fatty acids in human large intestine, portal, hepatic and venous blood. Gut 28, 1221-1227.

22. Cummings JH \& MacFarlane GT (1991) The control and consequences of bacterial fermentation in the human colon. $J$ Appl Bacteriol 70, 443-459.

23. Cummings JH (1982) Polysaccharide fermentation in the human colon. Colon and Nutrition: Proceedings of the 32nd Falk Symposium, pp. 91-102 [H Kasper and H Goebell, editors]. Hingham, MA: MTP Press.

24. Southgate DAT, Branch WJ, Hill MH, et al. (1976) Metabolic responses to dietary supplements of bran. Metabolism 25, 1129-1135.

25. Clausen JO, Borch-Johnsen K, Ibsen H, et al. (1996) Insulin sensitivity index, acute insulin response, and glucose effectiveness in a population-based sample of 380 young healthy Caucasians: analysis of the impact of gender, body fat, physical fitness and life-style factors. $J$ Clin Invest 98, 1195-1209.

26. Chiasson JL \& Rabasa-Lhoret R (2004) Prevention of type 2 diabetes: insulin resistance and $\beta$-cell function. Diabetes $\mathbf{5 3}$, Suppl. 3, S34-S38.

27. Brindle PA, Schooley DA, Tsai LW, et al. (1988) Comparative metabolism of branched-chain amino acids to precursors of juvenile hormone biogenesis in corpora allata of lepidopterous versus nonlepidopterous insects. $J$ Biol Chem 263, 10653-10657.

28. Scheppach W, Pomare EW, Elia M, et al. (1991) The contribution of the large intestine to blood acetate in man. Clin Sci 80, $177-182$.

29. Smith RF, Humphrys S \& Hockaday TD (1986) The measurement of plasma acetate by a manual or automated technique in diabetic and non-diabetic subjects. Ann Clin Biochem 23, $285-291$.

30. Wolever TM, Josse RG, Leiter LA, et al. (1997) Time of day and glucose tolerance status affect serum short-chain fatty acid concentrations in humans. Metabolism 46, 805-811.

31. Adam A, Levrat-Verny M-A, Lopez HW, et al. (2001) Whole wheat and triticale flours with differing viscosities stimulate cecal fermentations and lower plasma and hepatic lipids in rats. J Nutr 131, 1770-1776.

32. Rémésy C, Demingé C \& Chartier F (1980) Origin and utilization of volatile fatty acids in the rat. Reprod Nutr Dev 20, $1339-1349$.

33. Wolever TMS \& Chiasson JL (2000) Acarbose raises serum butyrate in subjects with impaired glucose tolerance. $\mathrm{Br} J$ Nutr 84, 57-61.

34. Knudsen KEB, Serena A, Canibe N, et al. (2003) New insight into butyrate metabolism. Proc Nutr Soc 62, 81-86.

35. Wolever TMS \& Robb PA (1992) Effect of guar, pectin, psyllium, soy polysaccharide and cellulose on breath hydrogen and methane in healthy subjects. Am $J$ Gastroenterol 87, 305-310.

36. Wolever TMS, ter Wal P, Spadafora P, et al. (1992) Guar, but not psyllium, increases breath methane and serum acetate concentrations in human subjects. Am J Clin Nutr 55, 719-722.

37. Cummings JH, Southgate DAT, Branch W, et al. (1978) Colonic response to dietary fibre from carrot, cabbage, apple, bran, and guar gum. Lancet i, 5-9.

38. El Oufir LE, Barry JL, Flourie B, et al. (2000) Relationships between transit time in man and in vitro fermentation of dietary fiber by fecal bacteria. Eur J Clin Nutr 54, 603-609.

39. Christensen DN, Bach Knudsen KE, Wolstrup J, et al. (1999) Integration of ileum cannulated pigs and in vitro fermentation to quantify the effect of diet composition on the amount of short-chain fatty acids available from fermentation in the large intestine. J Sci Food Agric 79, 755-762.

40. Boffa LC, Lupton JR, Mariani MR, et al. (1992) Modulation of colonic epithelial cell proliferation, histone acetylation and luminal short-chain fatty acids by variation of dietary fiber (wheat bran) in rats. Cancer Res 52, 5906-5912.

41. Duncan SH, Holtrop G, Lobley GE, et al. (2004) Contribution of acetate to butyrate formation by human fecal bacteria. $\mathrm{Br} J$ Nutr 91, 915-923.

42. Kleessen B, Stoof G, Proll J, et al. (1997) Feeding resistant starch affects fecal and caecal microflora and short-chain fatty acids in rats. J Anim Sci 75, 2453-2462.

43. van Loo J, Cummings J, Delzenne N, et al. (1999) Functional food properties of non-digestible oligosaccharides: a consensus report from the ENDO project (DGXII AIRII-CT94-1095). Br J Nutr 81, 121-132.

44. Eissele R, Göke R, Willemer S, et al. (1992) Glucagon-like peptide- 1 cells in the gastrointestinal tract and pancreas of rat, pig and man. Eur J Clin Invest 22, 283-291.

45. Massimino SP, McBurney MI, Field CJ, et al. (1998) Fermentable dietary fiber increases GLP-1 secretion and improves glucose homeostasis despite increased intestinal glucose transport capacity in healthy dogs. J Nutr 128, 1786-1793.

46. Kripke SA, Fox AD, Berman JJ, et al. (1989) Stimulation of intestinal mucosal growth with intracolonic infusion of shortchain fatty acids. JPEN 13, 109-116.

47. Cani PD, Hoste S, Guiot Y, et al. (2007) Dietary non-digestible carbohydrates promote L-cell differentiation in the proximal colon of rats. Br J Nutr $\mathbf{9 8}, 32-37$.

48. Karaki S, Tazoe H, Hayashi H, et al. (2008) Expression of the short-chain fatty acid receptor, GPR 43 , in the human colon. $J$ Mol Histol 39, 135-142.

49. Rask E, Olsson T, Soderberg S, et al. (2001) Impaired incretin response after a mixed meal is associated with insulin resistance in nondiabetic men. Diabetes Care 24, 1640-1645.

50. Verdich C, Toubro S, Buemann B, et al. (2001) The role of postprandial release of insulin and incretin hormones in mealinduced satiety - effect of obesity and weight reduction. Int $J$ Obes 25, 1206-1214.

51. Brubaker PL \& Vranic M (1987) Fetal rat intestinal cells in monolayer culture: a new in vitro system to study the glucagon-related peptides. Endocrinology 120, 1976-1985.

52. Anini Y \& Brubaker PL (2003) Role of leptin in the regulation of glucagon-like peptide-1 secretion. Diabetes 52, 252-259.

53. Robertson MD, Bickerton AS, Dennis AL, et al. (2005) Insulinsensitizing effects of dietary resistant starch and effects on skeletal muscle and adipose tissue metabolism. Am J Clin Nutr 82, 559-567. 